\title{
A Philanthropic Approach to Supporting Emergent Disaster Response and Recovery
}

Jeffrey Schlegelmilch, MPH, MBA; Jonathan Sury, MPH, CPH; Jeremy Brooks, MPH, CPH; Thomas Chandler, PhD

\section{ABSTRACT}

In August 2017, Hurricane Harvey struck the US Gulf Coast and caused more than US \$125 billion in damages in Texas. The loss of lives and the economic damages resulted in an outpouring of support for the recovery efforts in the form of federal assistance and private donations. The latter has supported more creative approaches to recovery. Organizations that normally would not receive funding were able to obtain resources to use in novel manners. Using the framework of Dynes typology to identify groups and their respective structures and tasks, this report from the field analyzes Hurricane Harvey and the financial support mechanisms used to support recovery efforts in Texas, what organizations were funded to do, and where they fit into Dynes typology. The authors close by noting the importance of these emerging organizations and the need to support diversity in funding disaster response and recovery efforts beyond large nonprofit organizations.

Key Words: hurricane, recovery, funding, philanthropy

$\mathrm{H}$ urricane Harvey made landfall in Texas on August 25, 2017, as a Category 4 hurricane. ${ }^{1}$ It carried winds of 130 miles per hour and dumped over 50 inches of rain in some areas. It is estimated that nearly 80000 homes experienced significant flooding, with over 800000 applications for assistance as of late September 20172,3; out of those, approximately 370000 were approved. ${ }^{2}$ With approximately US $\$ 125$ billion in damages, it was the second most expensive hurricane to venture ashore. ${ }^{4}$ Similar to past disasters, numerous formal and informal groups responded to Hurricane Harvey and continue to meet both the immediate and long-term needs of survivors.

When considering the disaster response and recovery to Hurricane Harvey as part of a disaster typology, there are a multitude of new ways in which established and emergent organizations collaborated within the health system. Dynes once called for the continual analysis and reconsideration of the ways in which such different organizations work together during and after disasters, and noted that this examination of human behavior is essential for understanding and improving upon disaster response and recovery efforts. He originally developed a typology that included 4 types: (1) established organized response, (2) expanding organized response, (3) extending organized response, and (4) emergent organized response ${ }^{5-7}$ (Figure 1).

For this article, the authors have categorized the organizational disaster response behavior of several different celebrity actors within the hurricane recovery who were active in the immediate aftermath of Hurricane Harvey. Specifically, 8 organizations received financial assistance from 2 celebrity donors under a pledge to support their presence on the ground providing direct assistance to survivors.

Programs within these organizations that were funded by other donors and/or were outside of the scope of the original pledge are not discussed here.

\section{FUNDED ORGANIZATIONS AND DYNES TYPOLOGY}

Recipients of the grants described were selected based on a needs assessment conducted by Dr Irwin Redlener, co-founder of the Children's Health Fund and director of the National Center for Disaster Preparedness at Columbia University's Earth Institute. The assessment was conducted via ground-site visits to the affected areas, discussions with federal partners coordinating relief efforts, and liaising with local non-profits responding to the storm. The assessment took place approximately 1 week after the storm made landfall. Criteria for organizations to receive support included the following:

- Active in assisting survivors of the storm

- Service for areas not able to be met by government agencies or quasi-government non-governmental institutions (eg, the American Red Cross) 


\section{Organizational Disaster Response Behavior of Several Different Actors Within the Health System.}

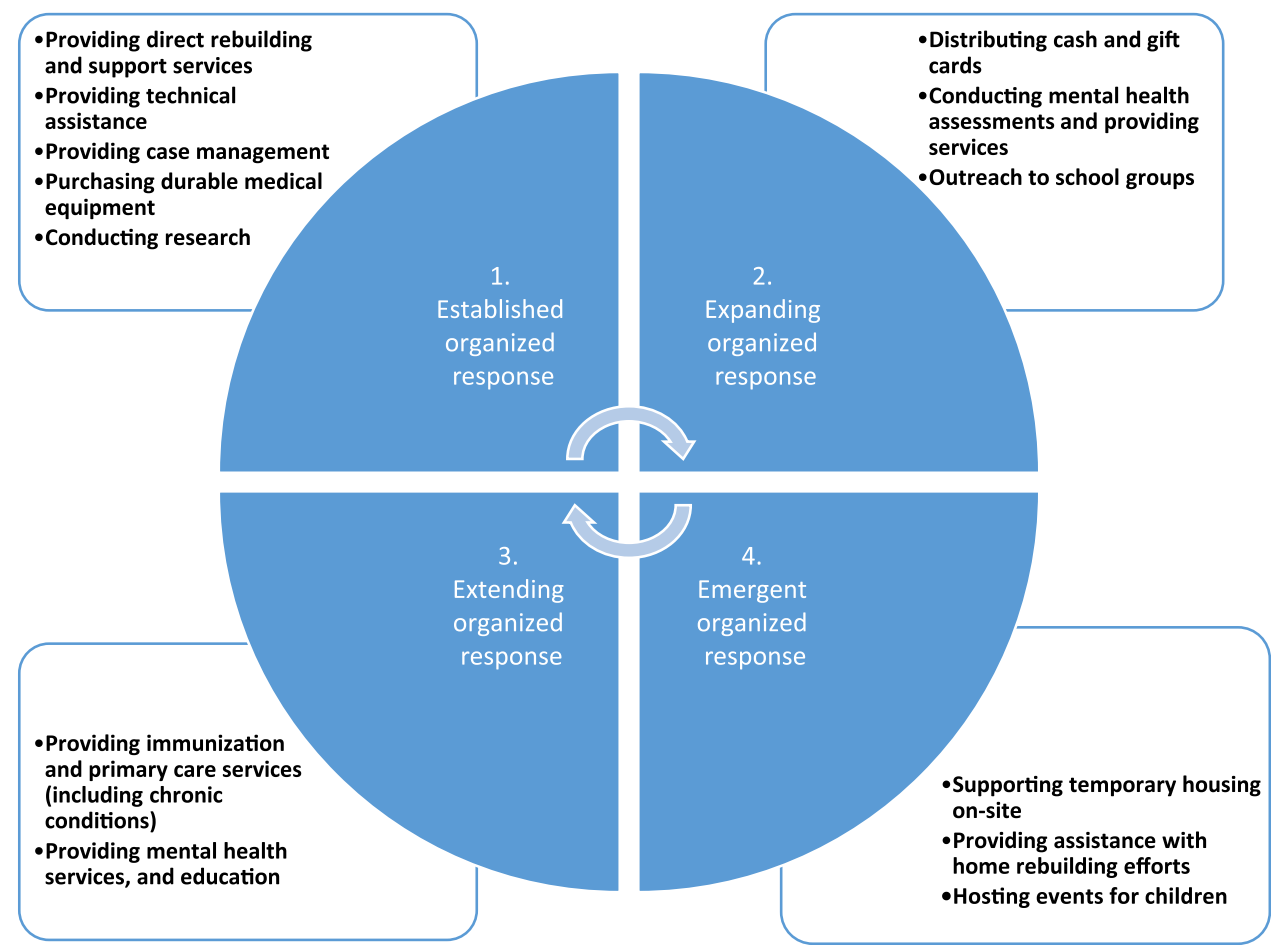

- Service to vulnerable populations (eg, the elderly, children, populations with special needs)

The portfolio of recipients represents all 4 types of organizational response elaborated in Dynes typology and has provided the following types of assistance:

- A national academic think-tank with a history of disaster response and recovery support, including the delivery of technical assistance, conducting of research, and the provision of training and planning resources. This group has managed these grants, advocated for policies that enhance the recovery efforts in the impacted areas in Texas, and supported partnerships and outreach between organizations. (Dynes Type 1)

- A faith-based disaster response network of over 175 churches and thousands of volunteers coordinating relief to disasters of all sizes that has been organized pre-disaster. The network is based in Texas and provides services regardless of a survivor's faith and provides direct services and resources to survivors, as well as organizes volunteers to assist with cleanup and rebuilding. This group has provided support with case management and individual assistance. The former includes emotional and spiritual support, support in completing Federal Emergency Management Agency (FEMA) applications, and referrals to local community resources. The latter includes support with rent, emergency housing, transportation, and clothing. As a result of their efforts, 193 families in the Greater Austin, Rockport, and Port Arthur areas have benefitted. (Dynes Type 1)
- An international relief organization that leverages volunteers, partner organizations, and local communities on tangible rebuilding. For Hurricane Harvey, they provided direct support for clearing debris and rebuilding homes in Texas. They have remediated homes through mucking and gutting, such as removing moldy and damaged possessions and parts of the home, like drywall, insulation, and flooring. This relief organization has helped 737 people, including families whose homes are being repaired and volunteers assisting with the cleanup. (Dynes Type 1)

- A cross-disability not-for-profit organization. They purchase and distribute durable medical equipment to people who lost their equipment during the storm. They purchased and provided items for people with disabilities and functional needs. The items included ramps, wheelchairs, mattresses, batteries, and iPads. Twenty-four people with disabilities were assisted by their efforts, and most of them had spinal cord injuries. (Dynes Type 1)

- A regional faith-based organization that provides services to all affected regardless of religion. They distribute cash and gift cards to families who have immediate financial needs with a particular emphasis on senior citizens. They have provided 16 households between US $\$ 200$ and US $\$ 2000$ each to assist with hotel expenses, trailer rental, replacing household items, and repairing homes. (Dynes Type 2)

- A national not-for-profit that provides clinical care to children in poverty throughout the country and provides disaster response and relief with a particular focus on the needs of children. They work with their clinical programs in the region 
to provide care, as well as to establish enhanced mental health services to children affected by the storm. This group directly supported a series of programs, including a pediatric hospital and child-focused programs in Austin, Dallas, and Houston. As a result of this support, 181 children have experienced mental health assessment and treatment, and 692 clinicians have been trained in Trauma and Grief Component Therapy. Additionally, there was outreach to 210 school groups. (Dynes Type 2)

- An academic medical center in Texas based outside of the directly affected areas, but that provides integrated services to parts of the region. They provide direct clinical resources to the affected areas in the greater Rockport and Port Aransas areas, with 2 trips weekly to various relief camps and shelters. They bring medical supplies, as well as physicians and nursing students to provide support. This center provides immunizations, primary care services (including chronic conditions), mental health services, and education. As a result of the center's work, 617 individuals received medical services, and an additional 750 people were educated on disease and immunization, nutrition counseling, and health promotion services. Over 200 nursing students have been involved in the program. (Dynes Type 3)

- An organization that was created after the hurricane made landfall on the property of a resident who lost a business, but whose home and property were relatively undamaged. They have supported temporary housing on-site, became a hub for donations, provided assistance with home rebuilding efforts, and hosted events for children. At its peak, the organization provided supplies to more than 800 people and hosted 38 displaced individuals on the property. In addition to direct funding, assistance was also provided for this group to file for tax exemption status as an established not-for-profit organization. (Dynes Type 4)

\section{IMPLICATIONS FOR FUTURE DISASTERS}

Oftentimes, disaster philanthropy focuses exclusively on large non-profits with a strong brand presence, or other large Type I organizations, despite well-documented shortcomings in their ability to meet the needs of survivors after a disaster. ${ }^{8-10}$ At best, these organizations represent only 1 facet of disaster relief and recovery, and at worst, are plagued by bureaucratic inefficiencies that can limit their impact in locally affected areas. ${ }^{11,12}$ Yet, more often than not, it is the emergent actors from within communities - the first boots on the ground suddenly presenting themselves during and after a disaster who may be particularly deserving of additional resources and attention. This facet, which requires new capacities, competencies, and capabilities to deal with, needs to be explored much further in future research, particularly in relation to the distribution of grant funding.

\section{CONCLUSION}

Whole community response and recovery requires funds that are available to a whole community of response organizations, not just those that are well established prior to the disaster. Further understanding of the direct impact and efficiency of funds translating into positive impacts is needed to determine how optimal this funding strategy is. However, this approach provides a compelling paradigm for funding disaster relief that may be complementary to conventional funding strategies.

\section{About the Authors}

The National Center for Disaster Preparedness, The Earth Institute, Columbia University, New York, New York.

Correspondence and reprint requests to Jeff Schlegelmilch, National Center for Disaster Preparedness, Columbia University, 215 W 125th Street, Suite 303, New York, NY 10027 (e-mail: js4645@columbia.edu).

\section{Conflict of Interest Statement}

The authors have no conflicts of interest to declare.

\section{REFERENCES}

1. NOAA. Major Hurricane Harvey - August 25-29, 2017. 2017. https:// www.weather.gov/crp/hurricane_harvey. Accessed November 25, 2017.

2. Lozano JA. Nearly 894,000 Texans apply for FEMA Harvey aid. Insurance J. 2017. https://www.insurancejournal.com/news/southcentral/2017/12/ 04/473035.htm. Accessed March 6, 2018.

3. Federal Emergency Management Agency (FEMA). Historic disaster response to Hurricane Harvey in Texas [press release]. FEMA, September 22, 2017.

4. National Oceanic and Atmospheric Administration (NOAA). Costliest U.S. tropical cyclones tables updated. In: Administration NOAA, ed. National Oceanic and Atmospheric Administration; 2018.

5. Dynes RR. Disaster reduction: the importance of adequate assumptions about social organization. Sociol Spectr. 1993;13(1):175-192.

6. Dynes RR. Organized behavior in disaster. Lexington, MA: Heath Lexington Books; 1970.

7. Chandler T, Abramson DM, Panigrahi B, et al. Crisis decision-making during Hurricane Sandy: an analysis of established and emergent disaster response behaviors in the New York metro area. Disaster Med Public Health Prep. 2016;10(3):436-442.

8. Chen D. New York City comptroller cites flaws in Hurricane Sandy recovery program. New York Times. March 31, 2015.

9. Elliott J, Eisinger J, Sullivan L. The Red Cross' secret disaster. ProPublica. October 29, 2014

10. Sullivan L. In search of the Red Cross' $\$ 500$ million in Haiti relief. 2015. https://www.npr.org/2015/06/03/411524156/in-search-of-the-red-cross500-million-in-haiti-relief. Accessed March 6, 2018.

11. Schneider SK. Governmental response to disasters: the conflict between bureaucratic procedures and emergent norms. 1992:135-145.

12. Quarantelli EL. Disaster related social behavior: summary of 50 years of research findings. Disaster Research Center, University of Delaware; 1999. 